Article

\title{
Large, Rapid Swelling of High-cis Polydicyclopentadiene Aerogels Suitable for Solvent-Responsive Actuators
}

\author{
Despoina Chriti ${ }^{1}$, Grigorios Raptopoulos ${ }^{1} \mathbb{D}$, Benjamin Brandenburg ${ }^{2}$ and \\ Patrina Paraskevopoulou 1,*(D) \\ 1 Laboratory of Inorganic Chemistry, Department of Chemistry, National and Kapodistrian University of \\ Athens, Panepistimiopolis Zografou, 15771 Athens, Greece; chritides@chem.uoa.gr (D.C.); \\ grigorisrap@chem.uoa.gr (G.R.) \\ 2 Dräger Safety AG \& Co. KGaA, Revalstraße 1, 23560 Lübeck, Germany; \\ Benjamin.Brandenburg@draeger.com \\ * Correspondence: paraskevopoulou@chem.uoa.gr; Tel.: +30-210-727-4381; Fax: +30-210-727-4782
}

Received: 11 April 2020; Accepted: 28 April 2020; Published: 2 May 2020

check for updates

\begin{abstract}
High-cis polydicyclopentadiene (PDCPD) aerogels were synthesized using ring opening metathesis polymerization (ROMP) of dicyclopentadiene (DCPD) with a relatively air-stable ditungsten catalytic system, $\mathrm{Na}\left[\mathrm{W}_{2}(\mu-\mathrm{Cl})_{3} \mathrm{Cl}_{4}(\mathrm{THF})_{2}\right] \cdot(\mathrm{THF})_{3}\left(\mathbf{W}_{2} ;\left(\mathrm{W}^{3} \mathrm{~W}\right)^{6+}, a^{\prime 2} e^{\prime 4}\right)$, and norbornadiene (NBD)as a co-initiator. These aerogels are compared in terms of chemical structure and material properties with literature PDCPD aerogels obtained using well-established Ru-based alkylidenes as catalysts. The use of NBD as a co-initiator enhances the degree of crosslinking versus the more frequently used phenylacetylene (PA), yielding materials with a controlled molecular structure that would persist solvent swelling. Indeed, those PDCPD aerogels absorb selected organic solvents (e.g., chloroform, tetrahydrofuran) and swell rapidly, in some cases up to 4 times their original volume within $10 \mathrm{~min}$, thus showing their potential for applications in chemical sensors and solvent-responsive actuators. The advantage of aerogels versus xerogels or dense polymers for these applications is their open porosity, which provides rapid access of the solvent to their interior, thus decreasing the diffusion distance inside the polymer itself, which in turn accelerates the response to the solvents of interest.
\end{abstract}

Keywords: tungsten; metal-metal bonds; ROMP; dicyclopentadiene; aerogels; solvent-responsive; swelling

\section{Introduction}

Aerogels are usually high-surface-area and extremely low-density materials, and they have become attractive for a wide range of applications, including thermal insulators [1-4], acoustic insulators [5,6], batteries [7,8], hydrogen storage [9], biomedicine [3,10-14], foods [3,15], sorbents [13,16-18], catalysts and catalyst supports $[3,17,19-22]$. The last decade has experienced an unprecedented growth of the types of aerogels available, ranging from inorganic [22-25] to organic (based on biopolymers [3,14,26-28] and synthetic polymers) and hybrid inorganic-organic aerogels [29-34]. The growth of synthetic polymer aerogels in particular has been extremely rapid and now that class includes aerogels based on a wide variety of phenolic resins [35-37], polyamides [38-40], polyimides [41-47], polyurethanes [48-53], polyureas [54-58] and polymers derived via ring opening metathesis polymerization (ROMP) [42,49,59-65].

ROMP (Scheme 1) belongs to a family of metathesis reactions that forms unsaturated, conjugated and non-conjugated polymers. It is considered as one of the most important synthetic tools in polymer and materials science and has been used for the industrial production of several commercial 
polymers [66-70]. Among them, polydicyclopentadiene (PDCPD), a crosslinked polymer prepared from the ROMP of dicyclopentadiene (DCPD), is particularly attractive because, among other things, the DCPD monomer is an inexpensive byproduct of the oil industry. As shown in Scheme 2, two mechanisms of crosslinking contribute to the formation of PDCPD either via metathesis or via radical addition to the double bonds of the pendant cyclopentene rings [71]. Such crosslinked PDCPD is a rigid polymer with excellent mechanical, chemical and physical properties. PDCPD aerogels combine the unique properties of aerogels with those of PDCPD polymers [59-65]. Thus, mechanically strong PDCPD-based aerogels can find applications as thermal and acoustic insulators [60], as well as low-density coatings [59,64].

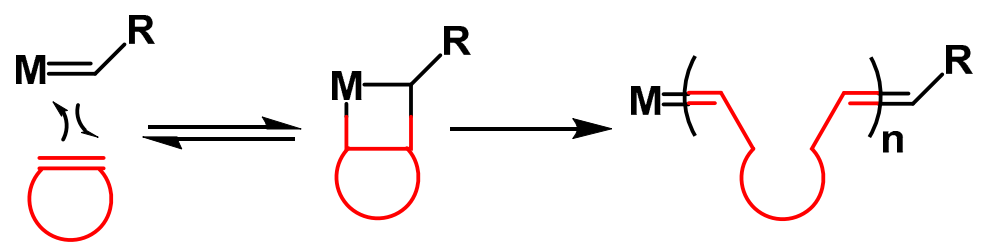

Scheme 1. Mechanism of ring-opening metathesis polymerization (ROMP).

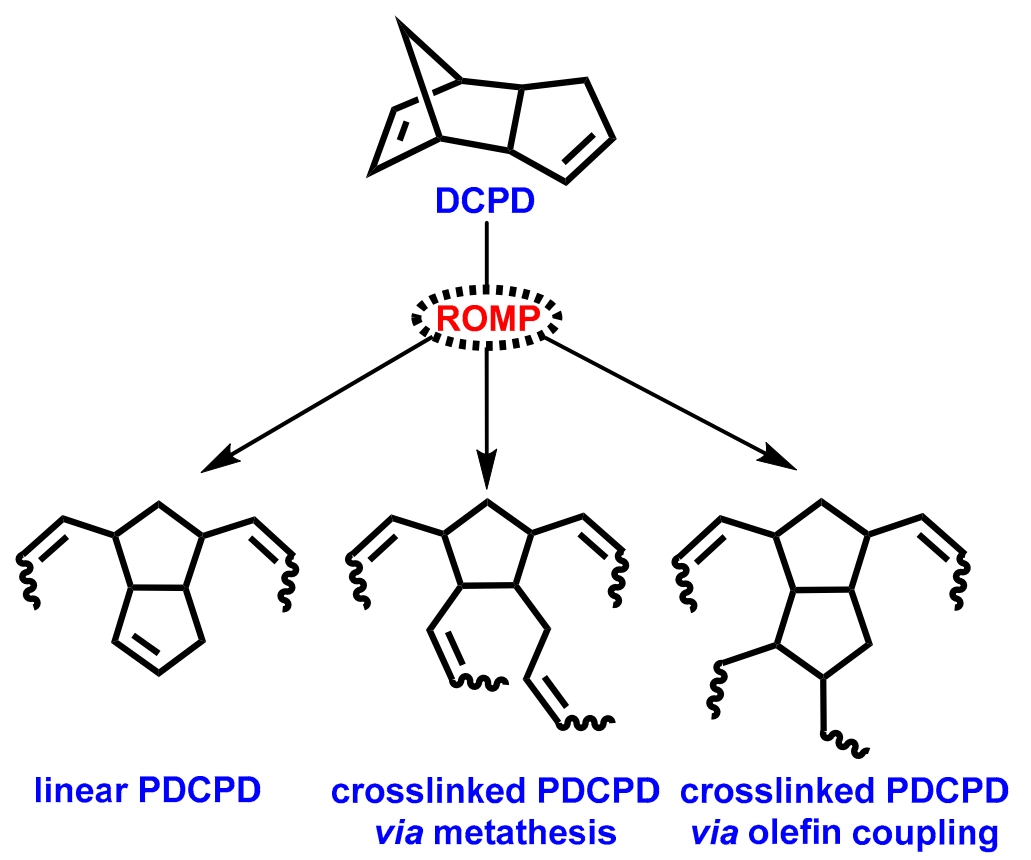

Scheme 2. ROMP of DCPD including two possible structures from crosslinking.

A wide variety of catalysts have been reported in the literature for the ROMP of DCPD. Most of those catalysts are based on mononuclear complexes of transition metals [59,61,72-74], which can be catalytically active per se, or after activation with a co-initiator. Although less widely known, bimetallic clusters with metal-metal bonds have also been employed as ROMP catalysts. For example, both $\mathrm{Na}\left[\mathrm{W}_{2}(\mu-\mathrm{Cl})_{3} \mathrm{Cl}_{4}(\mathrm{THF})_{2}\right] \cdot(\mathrm{THF})_{3}\left(\mathbf{W}_{2} ;\left(\mathrm{W}^{3} \mathrm{~W}\right)^{6+}, a^{\prime 2} e^{\prime 4}\right)[75-79]$ and $\left(\mathrm{Ph}_{4} \mathrm{P}\right)_{2}\left[\mathrm{~W}_{2}\left(\mu-\mathrm{Br}_{3} \mathrm{Br}_{6}\right]\left(\mathbf{W}_{2}-\mathbf{B r}\right.\right.$; $\left.\left(\mathrm{W}^{2.5} \mathrm{~W}\right)^{7+}, a^{\prime 2} e^{\prime 3}\right)[80]$ show high catalytic activity towards the metathesis polymerization of alkynes, as well as the polymerization of many cycloolefins. $\mathbf{W}_{2}$, in particular, yields polymers with a high-cis double bond content [75-79]. The addition of phenylacetylene (PA) as a co-initiator improves the catalytic activity, while the high-cis stereoselectivity is retained [75,78]. Regarding PDCPD, the subject matter of this report, $\mathbf{W}_{\mathbf{2}}$-based catalytic systems do provide highly crosslinked and mostly-cis polymers $[75,78,81]$. Owing to their mostly-cis structure, PDCPD xerogels obtained with the $\mathbf{W}_{2} / \mathbf{P A}$ catalytic system have shown an ability for extreme volumetric swelling in various organic solvents 
(up to more than $100 \times$ the volume of the original xerogel), and selective solvent uptake has been reported from both miscible and immiscible mixtures [75,81].

In this study, we describe the synthesis and characterization of PDCPD aerogels via ROMP of DCPD using $\mathbf{W}_{\mathbf{2}}$ as catalyst and norbornadiene (NBD) as co-initiator. Similar to PA, NBD can enhance the activity of $\mathbf{W}_{2}$, and polymerization with either PA or NBD as co-initiator proceeds faster. In contrast to PA, however, NBD has the advantage of yielding crosslinked polymers, while the $\mathbf{W}_{2} / \mathbf{P A}$ system yields polymer chains that contain linear polyphenylacetylene segments. Thus, for example, $\mathbf{W}_{2} / \mathrm{NBD}$ catalyzes the ROMP of norbornene yielding materials with a controlled molecular structure (star-shaped structure) via the "core-first" synthesis method [79], which is not possible with the $\mathbf{W}_{2} / \mathbf{P A}$ system. Another advantage of the higher degree of crosslinking obtained with the $\mathbf{W}_{2} / \mathrm{NBD}$ catalytic system is expected to be some rubber-like elasticity that would hold the resulting polymer together after solvent swelling, which in turn would increase reversibility in applications such as sensors and actuators (see next paragraph). In this paper, the configuration and material properties of PDCPD aerogels synthesized using the $\mathbf{W}_{2} / \mathbf{N B D}$ catalytic system are compared to those of PDCPD xerogels and aerogels synthesized not only with the $\mathbf{W}_{2} / \mathbf{P A}$ catalytic system [75,81], but also with first and second generation Grubbs' catalysts (Ru-I and Ru-II, respectively-Scheme 3), which are known to yield mostly trans PDCPD [63,75].

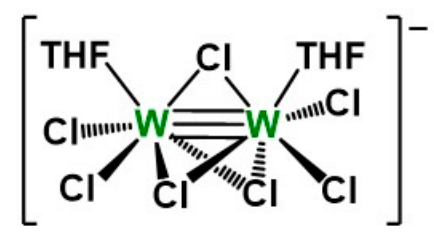

$\mathrm{W}_{2}$

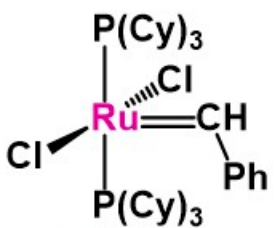

Ru-I

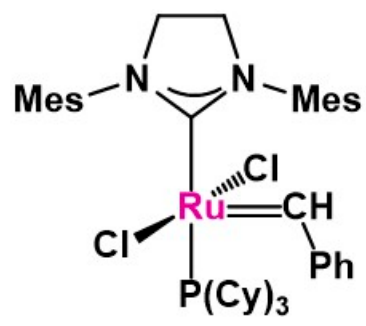

Ru-II

Scheme 3. The structures of $\mathrm{Na}\left[\mathrm{W}_{2}(\mu-\mathrm{Cl})_{3} \mathrm{Cl}_{4}(\mathrm{THF})_{2}\right] \cdot(\mathrm{THF})_{3}\left(\mathbf{W}_{\mathbf{2}}\right)$, Grubbs catalyst 1 st $(\mathbf{R u}-\mathbf{I})$ and 2nd generation (Ru-II).

At last, we have shown recently that mostly-cis PDCPD xerogels synthesized with the $\mathbf{W}_{2} / \mathbf{P A}$ catalytic system have the ability to absorb large amounts of selected organic solvents (neat or from mixtures) and swell a lot, sometimes up to $>100 \times$ the volume of the dry xerogel [75,81]. This property was correlated with the mostly-cis structure of the polymer chain, Ru-I- and Ru-II-derived PDCPD aerogels with a significant trans-content swell less or do not swell at all [75,81]. In continuation of that study, and because of the growing interest in using crosslinked polymers in the form of gels in chemical sensors and actuators [82-87], herein we evaluate highly-crosslinked mostly-cis PDCPD aerogels synthesized using the catalytic system $\mathbf{W}_{2} / \mathrm{NBD}$ for potential use in sensors and solvent-responsive actuators. The advantage of aerogels versus xerogels or dense polymers for these applications is their open porosity, which provides rapid access of the solvent to their interior, which in turn decreases the diffusion distance inside the rigid polymer itself, thus accelerating the response to the solvents of interest.

\section{Materials and Methods}

\subsection{Materials and Physical Measurements}

DCPD and NBD were purchased from Sigma-Aldrich (Saint louis, MO, USA). $\mathbf{W}_{\mathbf{2}}$ was prepared according to literature procedures [88]. DCPD and NBD were distilled over $\mathrm{CaH}_{2}$ under vacuum. Dichloromethane was distilled over $\mathrm{P}_{4} \mathrm{O}_{10}$ and was degassed using three freeze-pump-thaw cycles. Solvents for washings of wet-gels (tetrahydrofuran (THF), pentane and acetone) and for all swelling experiments were used as received. The synthesis of $\mathbf{W}_{2}$ and the preparation of the sol $\left(\mathbf{W}_{2}, \mathbf{N B D}\right.$, 
DCPD, $\mathrm{CH}_{2} \mathrm{Cl}_{2}$ ) were performed under a pure argon atmosphere, using Schlenk techniques on an inert gas/vacuum manifold or in a drybox $\left(\mathrm{O}_{2}, \mathrm{H}_{2} \mathrm{O}<1 \mathrm{ppm}\right)$.

Attenuated Total Reflection Fourier Transform IR (ATR-FTIR) spectra (525-4000 $\mathrm{cm}^{-1}$ ) were measured on a Fourier-transform instrument (Equinox 55 by Bruker $\mathrm{GmbH}$, Ettlingen, Germany) equipped with a single-reflection diamond ATR accessory (DuraSamplIR II by SensIR Technologies, currently Smiths Detection, Edgewood, MD, USA). Contact between the powder samples and the tip was ensured by applying a suitable level of pressure. The spectra were obtained at an optical resolution of $4 \mathrm{~cm}^{-1}$ and are averages of 100 scans. FT-Raman spectra were obtained on a Fourier-transform instrument (RFS 100 by Bruker Optics) employing for excitation ca. $300 \mathrm{~mW}$ of the Nd:YAG $1064 \mathrm{~nm}$ line in a backscattering geometry. The spectra were obtained at a resolution of $4 \mathrm{~cm}^{-1}$ and are averages of ca. 5000-8000 scans. ${ }^{13} \mathrm{C}$ cross-polarization magic angle spinning (CPMAS) NMR spectra were obtained with a $600 \mathrm{MHz}$ Varian spectrometer (Varian, Palo Alto, CA, USA) operating at $150.80 \mathrm{MHz}$ for ${ }^{13} \mathrm{C}$. The sample spinning rate used was $5 \mathrm{KHz}$ and the temperature was set at $25^{\circ} \mathrm{C}$.

Thermogravimetric analysis (TGA) was conducted with a Mettler-Toledo TGA (Schwerzenbach, Switzerland), using alumina crucibles. An empty alumina crucible was used as a reference. Samples were heated from ambient temperature to $800{ }^{\circ} \mathrm{C}$ in a $50 \mathrm{~mL} / \mathrm{min}$ flow of $\mathrm{N}_{2}$ at a heating rate of $10{ }^{\circ} \mathrm{C} / \mathrm{min}$.

$\mathrm{N}_{2}$-sorption measurements were made on a Micromeritics Tristar II 3020 surface area and porosity analyzer (Micromeritics, Norcross, GA, USA). Skeletal densities $\left(\rho_{\mathrm{s}}\right)$ were determined by He pycnometry, using a Micromeritics AccuPyc II 1340 pycnometer (Micromeritics, Norcross, GA, USA). Bulk densities $\left(\rho_{\mathrm{b}}\right)$ of the samples were calculated from their mass and natural dimensions.

Supercritical fluid (SCF) $\mathrm{CO}_{2}$ drying was carried out in an autoclave (E3100, Quorum Technologies, East Sussex, UK). Wet-gels were placed in the autoclave at $12{ }^{\circ} \mathrm{C}$ and were covered with acetone. Liquid $\mathrm{CO}_{2}$ was allowed to flow in the autoclave and at the same time acetone was removed making sure that the samples were always submerged under liquid. The process was repeated 5 times, once every $30 \mathrm{~min}$. Afterwards, the temperature of the autoclave was raised to $45^{\circ} \mathrm{C}$ and was maintained for $1 \mathrm{~h}$. Finally, the pressure was gradually released, allowing $\mathrm{SCF} \mathrm{CO}_{2}$ to escape as a gas, leaving dry-gels (aerogels).

Scanning electron microscopy (SEM) was carried out on dried aerogel samples coated with Au and attached on a conductive double-sided adhesive carbon tape, using a Jeol JSM 5600 SEM instrument (Tokyo, Japan). The system was operating at $20 \mathrm{kV}, 0.5 \mathrm{nA}$ and $50 \mathrm{~s}$ time of analysis.

\subsection{Synthesis of PDCPD Xerogels and Aerogels Using the Catalytic System $\mathbf{W}_{2} / \mathbf{N B D}$}

All formulations are shown in Table S1. In a typical procedure, NBD was added to a solution of $\mathbf{W}_{\mathbf{2}}$ in dichloromethane, followed by the addition of DCPD. The mixture was stirred vigorously at room temperature for $1 \mathrm{~min}$ and then was poured into polypropylene molds. All solutions gelled within $15 \mathrm{~min}$. The resulting wet-gels were aged in their molds for $24-28 \mathrm{~h}$ at room temperature. Subsequently, wet-gels were removed from their molds and were solvent-exchanged with THF $(4 \times, 8 \mathrm{~h}$ per wash cycle, $4 \times$ the volume of the gels) and then with (a) pentane $(4 \times, 8 \mathrm{~h}$ per wash cycle, $4 \times$ the volume of the gels) and they were dried in the oven at $50{ }^{\circ} \mathrm{C}$ for $4 \mathrm{~h}$ to provide PDCPD xerogels or (b) acetone ( $4 \times, 8 \mathrm{~h}$ per wash cycle, $4 \times$ the volume of the gels) and they were dried from $\mathrm{SCF} \mathrm{CO}_{2}$ to provide PDCPD aerogels.

\subsection{Study of the Swelling Behavior of PDCPD Aerogels}

Thin disks (0.9-1.0 $\mathrm{cm}$ in diameter and 1-2 mm thick) of PDCPD aerogels of $0.1 \mathrm{~mL}$ initial volume were placed in graduated closed glass tubes, each containing $5 \mathrm{~mL}$ of an organic solvent (toluene, dichloromethane, chloroform, chlorobenzene, bromobenzene, THF, 1-bromobutane, ethyl bromide, ethylene dichloride, $m$-xylene, $p$-xylene and mesitylene). They were kept in the solvent for $2 \mathrm{~h}$. The volume increase of the wet-gels in each solvent was measured every $10 \mathrm{~min}$ for the first hour and it was determined by the volume decrease of each solvent when the wet-gel was taken out from the graduated glass tube. 


\section{Results and Discussion}

\subsection{Preparation of PDCPD Xerogels and Aerogels Using the Catalytic System $\mathbf{W}_{2} / \mathrm{NBD}$}

The synthesis of PDCPD wet-gels was carried out at room temperature under Ar atmosphere (Scheme 4). Wet-gels were either dried in the oven at $50{ }^{\circ} \mathrm{C}$ for $4 \mathrm{~h}$ or with $\mathrm{SCF} \mathrm{CO}_{2}$, yielding PDCPD xerogels and aerogels, respectively. All formulations are shown in Table S1. The weight percent of DCPD was the same for all samples $(20 \% w / w)$. Higher concentrations of monomer provided materials with bulk densities $>1 \mathrm{~g} \mathrm{~cm}^{-3}$. Attempts to work with lower concentration sols (e.g., 10 or $5 \%$ of DCPD) provided wet-gels (within 24 to $48 \mathrm{~h}$ ) that were not very sturdy and could not be handled easily during post-gelation solvent exchange. The most likely explanation of this behavior is the higher amount of linear PDCPD, which is soluble in common organic solvents. Previous works by both our group and others $[71,89,90]$ have shown the formation of linear PDCPD in low DCPD concentrations. Unreacted monomer and soluble oligomers in the wet-gels were dissolved away during post-gelation solvent exchanges with THF (as shown from the ${ }^{1} \mathrm{H}$ NMR spectra of the washes). Different molar ratios of $\mathbf{W}_{2} / \mathbf{N B D}$ were tested for a constant concentration of the monomer (20\% $\left.w / w\right): 1 / 5,1 / 10,1 / 20$, $1 / 30$ and 1/40. Experiments with a molar ratio of $\mathbf{W}_{2} / \mathbf{N B D}$ equal to $1 / 5$ did not gel, while all other ratios provided sturdy wet-gels. By comparison of the material properties of PDCPD aerogels (Table 1), the optimal $\mathbf{W}_{2} / \mathrm{NBD}$ molar ratio was $1 / 10$. Thereby, all subsequent work with that catalyst was carried out with that molar ratio.

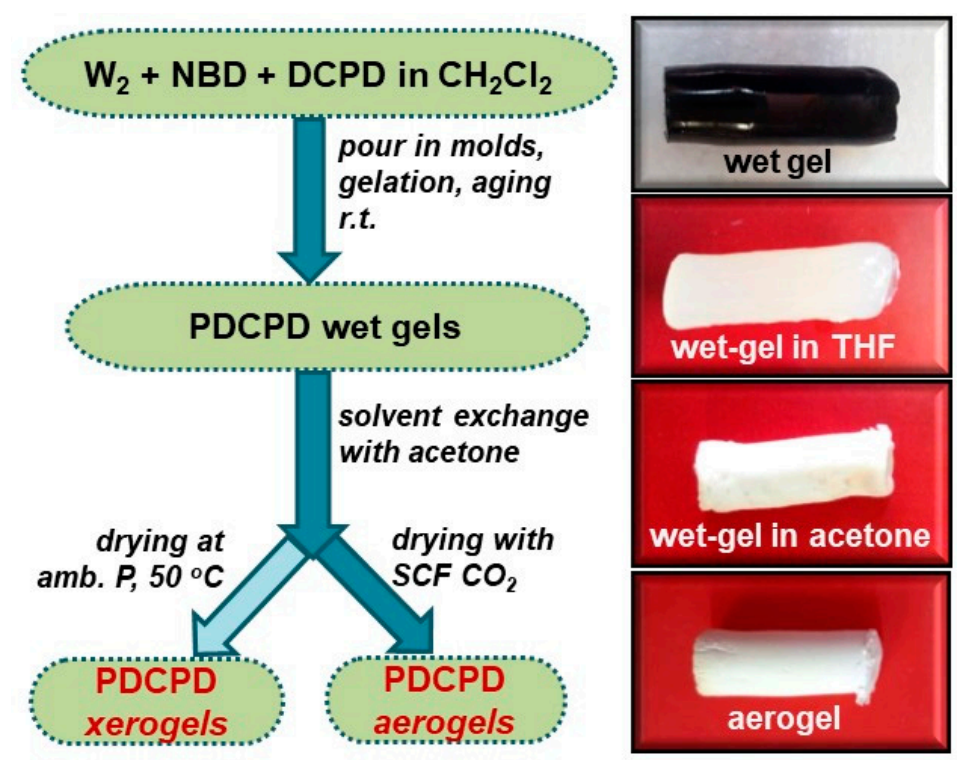

Scheme 4. Synthetic route for PDCPD sol-gel materials (xerogels and aerogels) from the ROMP of DCPD with $\mathbf{W}_{2} / \mathrm{NBD}$. This work is focusing on aerogels. Representative photographs of monoliths $(0.9-1.0 \mathrm{~cm}$ in diameter, $2.5-3.0 \mathrm{~cm}$ in length) at different stages of processing are shown on the right.

\subsection{Physicochemical Characterization of PDCPD Xerogels and Aerogels}

The structure and the configuration of the polymeric chain of PDCPD xerogels and aerogels were studied with spectroscopic techniques (ATR-FTIR and FT-Raman-Figure 1 and ${ }^{13}$ C CPMAS NMR-Figure 2) and their thermal stability with thermogravimetric analysis (TGA). As expected, xerogels and aerogels are chemically identical. Therefore, the characterization data for PDCPD aerogels are presented below, along with SEM and $\mathrm{N}_{2}$ sorption data, which provided information about the porous network of the aerogels. As expected, the chemical characterization showed that the PDCPD aerogels of this study were very similar with PDCPD xerogels obtained previously with $\mathbf{W}_{2} / \mathbf{P A}$ [75], following the characteristic features of reactivity of $\mathbf{W}_{\mathbf{2}}$ [75-79], and confirmed the high-cis content of the polymer chain. For comparison purposes, figures showing the spectra of PDCPD materials 
obtained with catalytic systems $\mathbf{W}_{2} / \mathbf{N B D}, \mathbf{W}_{2} / \mathbf{P A}$ (which provides mostly-trans $\mathbf{P D C P D}$ ), and $\mathbf{R u} \mathbf{u} \mathbf{I}$ (which provides mostly-trans PDCPD) [63,75] are given in the Supporting Information (Figure S1 and Figure S2).
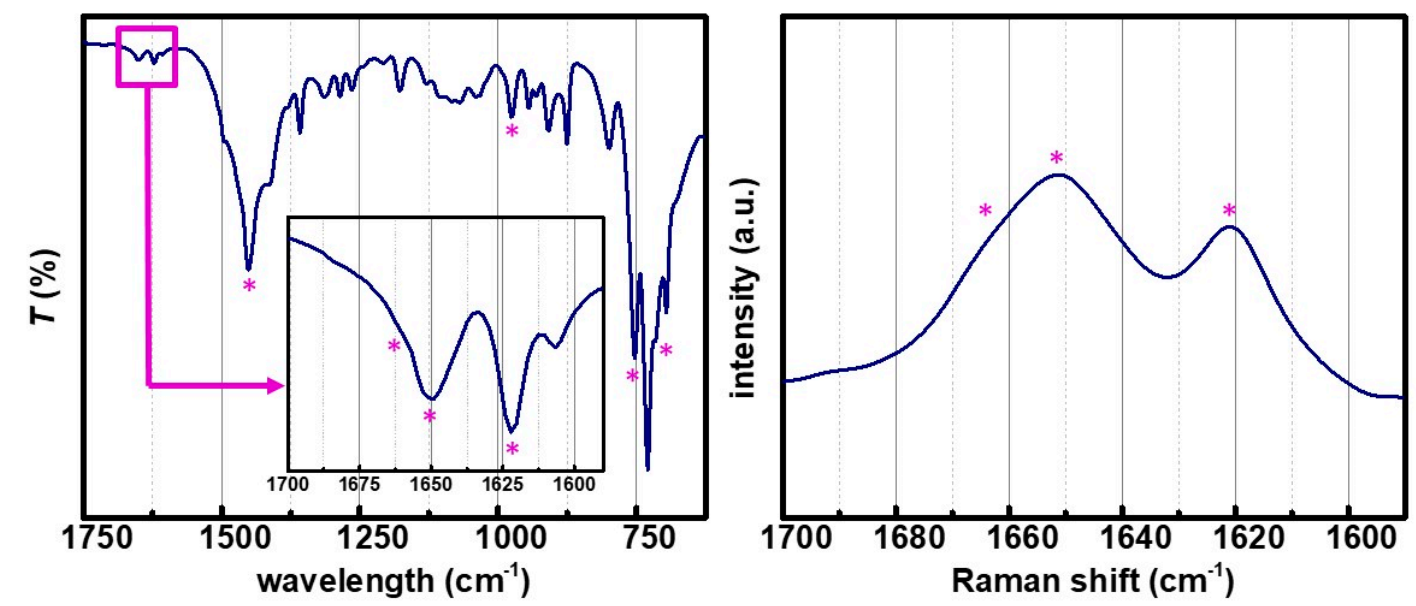

Figure 1. ATR-FTIR (left) and FT-Raman (right) spectra of PDCPD aerogels obtained from the ROMP of DCPD with $\mathrm{W}_{2} / \mathrm{NBD}$.

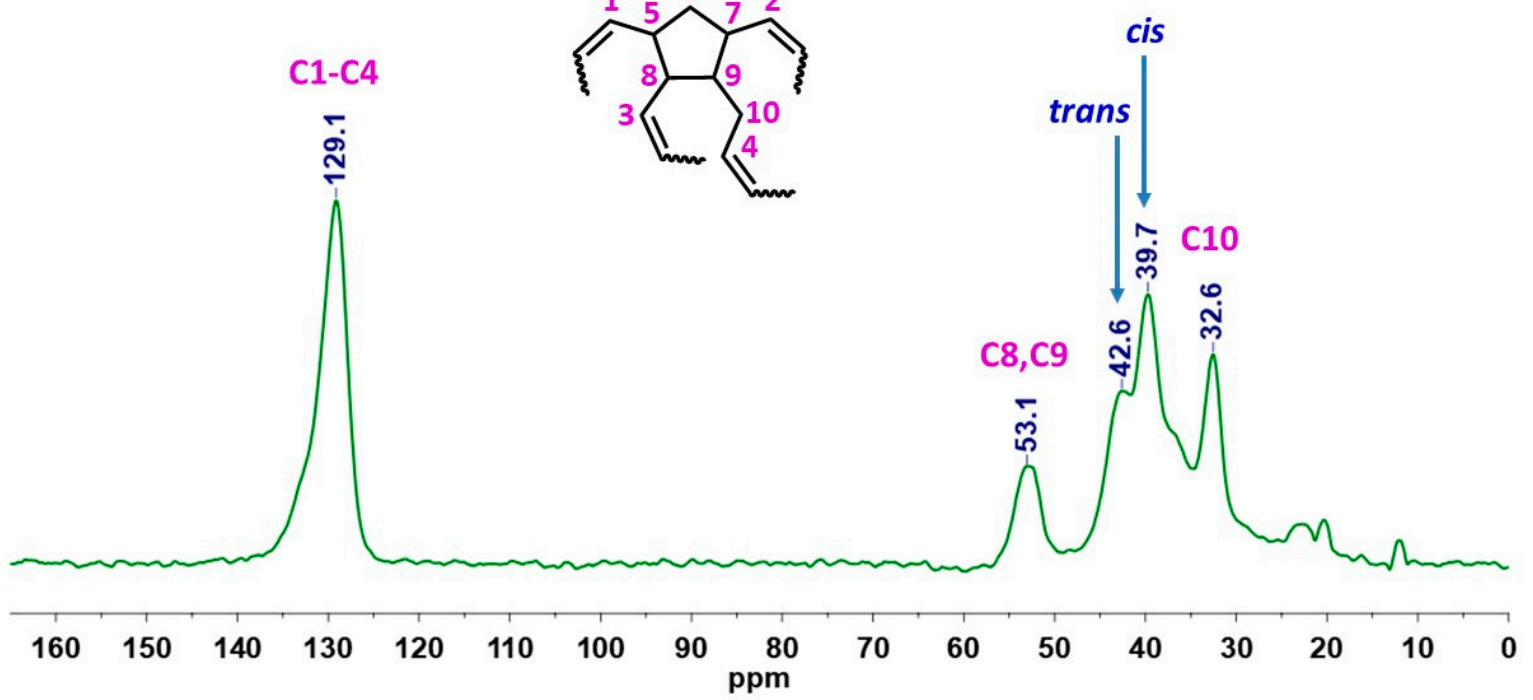

Figure 2. ${ }^{13} \mathrm{C}$ CPMAS NMR spectrum of PDCPD aerogels obtained from the ROMP of DCPD with $\mathrm{W}_{2} / \mathrm{NBD}$.

More specifically, ATR-FTIR spectra (Figure 1 and Figure S1, top) showed the stretching vibration of trans and cis $\mathrm{C}=\mathrm{C}$ bonds at $1660 \mathrm{~cm}^{-1}$ and at $1650 \mathrm{~cm}^{-1}$, respectively, and deformation vibrations of $\mathrm{C}-\mathrm{H}$ bonds on trans and cis double bonds at 976 and $750 \mathrm{~cm}^{-1}$, respectively. A shoulder at $710 \mathrm{~cm}^{-1}$ proved the existence of unreacted pendant cyclopentene groups, pointing out the presence of linear PDCPD segments in the polymer backbone. The relative intensity of the bands related to cis/trans bonds, in comparison to the spectra of PDCPD obtained with catalytic systems $\mathbf{W}_{2} / \mathbf{P A}$ and Ru-I (Figure S1, top), suggested that $\mathbf{W}_{2} / \mathbf{N B D}$ and $\mathbf{W}_{2} / \mathbf{P A}$ provided PDCPD with the same configuration, i.e., mostly-cis [75]. In addition, Raman spectra of both materials were almost identical (Figure 1 and Figure S1, bottom), showing two characteristic bands at 1650 and $1622 \mathrm{~cm}^{-1}$, which were attributed to the acyclic cis double bonds of the polymer network and to the cyclic cis cyclopentene double bonds, 
respectively, and a small shoulder at $1664 \mathrm{~cm}^{-1}$, corresponding to the $v(\mathrm{C}=\mathrm{C})$ of the trans double bonds of the polymeric chain $[75,91,92]$.

In agreement with ATR-FTIR and FT-Raman spectroscopy, ${ }^{13} \mathrm{C}$ CPMAS NMR spectroscopy (Figure 2 and Figure S2) also confirmed the high-cis configuration of PDCPD aerogels. The peak at $40 \mathrm{ppm}$ was assigned to cis double bonds of the polymeric chain and prevailed over the peak at $44 \mathrm{ppm}$, which was assigned to trans double bonds of the polymeric chain $[63,75]$. The exact determination of the cis/trans ratio was not possible due to overlapping of the two peaks. However, the stereoselectivity of each catalytic system is rather straightforward (Figure 2).

The thermal stability of the PDCPD aerogels was investigated using thermogravimetric analysis (TGA) under nitrogen (Figure S3, left). TGA curves for materials obtained with the three catalytic systems were very similar and showed that the thermal decomposition can be divided into two steps. For the PDCPD aerogels of this study, a very small weight loss (2\%) was observed during the first step, from 25 to $420^{\circ} \mathrm{C}$, corresponding to the evaporation and decomposition of unreacted monomers and oligomers. The second and main degradation step happened after $460{ }^{\circ} \mathrm{C}$ and resulted in a residue of $18 \%$. As can be seen in differential thermogravimetry (Figure S3, right), a shoulder appeared at $470{ }^{\circ} \mathrm{C}$, indicating a bimodal and more complex thermal decomposition mechanism than in the case of PDCPD obtained with Ru-I.

PDCPD xerogels synthesized with $\mathbf{W}_{2} / \mathrm{NBD}$ had no porosity or little porosity (for example, for a molar ratio of $\mathbf{W}_{2} / \mathrm{NBD}$ equal to $1 / 10$, the bulk density was around $1 \mathrm{~g} \mathrm{~cm}^{-3}$ and the skeletal density was $1.1 \mathrm{~g} \mathrm{~cm}^{-3}$, therefore the porosity was only $\left.9 \% v / v\right)$. Therefore, and despite their more straightforward preparation, PDCPD xerogels were not considered further for this work. Selected material properties for PDCPD aerogels are summarized in Table 1. Lower bulk density, higher porosity, higher BET (Brunauer-Emmett-Teller) surface area and smaller particle sizes were obtained for PDCPD aerogels synthesized using the lowest $\mathbf{W}_{2} / \mathbf{N B D}$ molar ratio $(1 / 10)$. The skeletal density was also lower, compared to the higher $\mathbf{W}_{2} / \mathbf{N B D}$ molar ratios, as a result of the incorporation of more or longer polynorbornadiene (PNBD) segments in the polymer chain. The shape of the $\mathrm{N}_{2}$-sorption isotherm (i.e., no saturation, narrow hysteresis loop; Figure 3) and the fact that $V_{\text {Total }}>>V_{1.7-300 \mathrm{~nm}}$ (Table 1) indicate that our materials are macroporous, in agreement with the literature [63]. Average pore diameters were calculated using the $4 V / \sigma$ method. $V$ was set either as the maximum volume of $\mathrm{N}_{2}$ adsorbed along the isotherm or as the volume $\left(V_{\text {Total }}\right)$ calculated from the bulk and the skeletal density of the corresponding materials (Table 1 ). Average pore diameter using $V_{\text {Total }}$ were higher and they increased with decreasing bulk density. From the BJH (Barrett-Joyner-Halenda) method, the peak maximum was at $40 \mathrm{~nm}$.

Table 1. Selected material properties of PDCPD aerogels obtained from the ROMP of DCPD with three different catalytic systems.

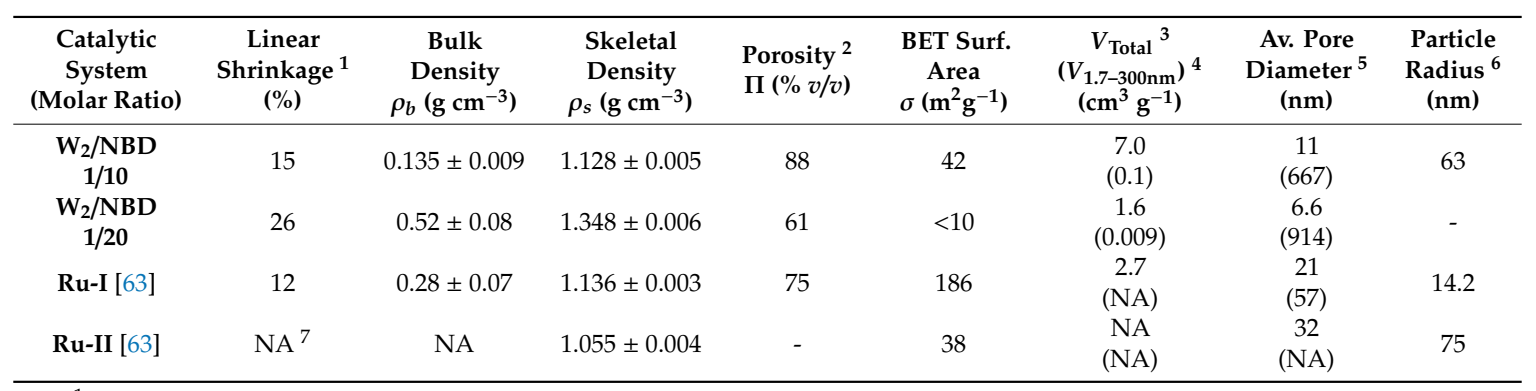

${ }^{1}$ Linear shrinkage after SCF drying calculated according to formula $\left(y_{1}+y_{2}\right) / 2$, where $y_{1}=100-\left[\left(h_{\text {fin }} / h_{\mathrm{st}}\right) \times 100\right]$ and $y_{2}=100-\left[\left(d_{\text {fin }} / d_{\mathrm{st}}\right) \times 100\right] ; h$ : height, $d$ : diameter. ${ }^{2}$ Porosity calculated according to formula $100 \times\left(\rho_{\mathrm{s}}-\rho_{\mathrm{b}}\right) / \rho_{\mathrm{s}}$, where $\rho_{\mathrm{s}}$ : skeletal density and $\rho_{\mathrm{b}}$ : bulk density. ${ }^{3}$ Volume calculated according to formula $1 / \rho_{\mathrm{b}}-1 / \rho_{\mathrm{s}} .{ }^{4}$ Cumulative volume of pores between 1.7 and $300 \mathrm{~nm}$ from $\mathrm{N}_{2}$-sorption data and the $\mathrm{BJH}$ desorption method. ${ }^{5}$ Calculated using the $4 V / \sigma$ method; $V$ was set equal to the maximum volume of $\mathrm{N}_{2}$ adsorbed along the isotherm as $P / P_{\mathrm{o}} \rightarrow 1.0$. For the number in parenthesis, $V$ was set equal to $V_{\text {Total }}$ from the previous column. ${ }^{6}$ Particle size calculated according to formula $r=3 /\left(\rho_{\mathrm{s}} \times \sigma\right) .{ }^{7}$ Deformed cylinder; not measured. 


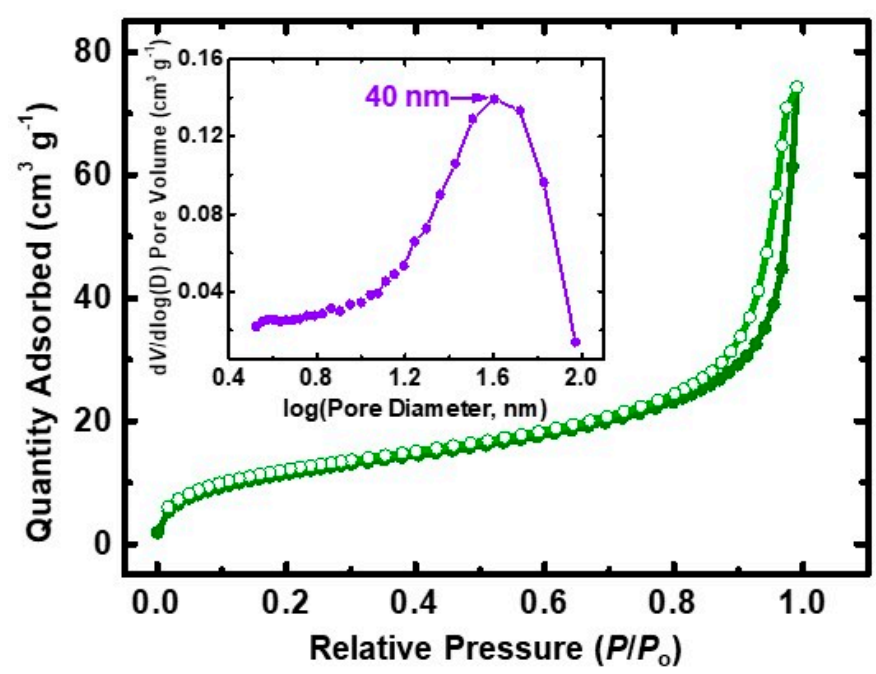

Figure 3. $\mathrm{N}_{2}$-sorption isotherm for PDCPD aerogels obtained from the ROMP of DCPD with $\mathbf{W}_{2} / \mathrm{NBD}$ (Table 1, entry 1). Inset: pore size distribution using the BJH method.

Table 1 also includes selected material properties of PDCPD aerogels from the literature [63], synthesized with Ru-I and Ru-II. All comparisons are made for aerogels from sols of the same concentration $(20 \% w / w)$. PDCPD aerogels of this study ( $\left.\mathbf{W}_{2} / \mathbf{N B D} 1 / 10\right)$ have lower bulk density and higher porosity, but significantly lower BET surface area compared to PDCPD aerogels from Ru-I. On the other hand, they have similar BET surface area $\left(42 \mathrm{vs.} 38 \mathrm{~m}^{2} / \mathrm{g}\right)$ and particle size (63 vs. $75 \mathrm{~nm}$ ), and lower average pore diameter (11 vs. $32 \mathrm{~nm}$ ) compared to PDCPD aerogels from Ru-II. It seems that high-cis PDCPD aerogels (from $\mathbf{W}_{2} / \mathbf{N B D}$ ) have similar properties to high-trans PDCPD aerogels (from Ru-II), and they have three advantages: (a) they are sturdy and well-shaped (Scheme 4), while Ru-II-derived aerogels were deformed, (b) the $\mathbf{W}_{\mathbf{2}} / \mathbf{N B D}$ catalytic system is more cost-efficient compared to Ru-II, and (c) high-cis PDCPD aerogels can be used for applications related to environmental remediation (see next section).

The morphology of PDCPD aerogels prepared with $\mathbf{W}_{2} /$ NBD was investigated with SEM, which revealed a beaded fibrous microstructure (Figure 4). That morphology is different from that of PDCPD aerogels prepared with the same sol concentration $(20 \% w / w)$ using Ru-I or Ru-II catalysts [63]. Those materials were macroporous, and although they were also fibrous, no beads could be seen along the fibers even at higher magnifications. It is suggested that this difference in morphology is related to the different cis/trans configuration of the polymers, which is translated to different mechanisms of phase separation along gelation. Differences in morphologies that could be attributed to the configuration of the polymer chains have also been observed in norbornene/norbornadiene copolymers. Furthermore, high-cis copolymers, obtained with $\mathbf{W}_{2} / \mathbf{P A}$ [79], had different morphologies than copolymers with a 50/50 cis/trans double bond ratio, obtained with Ru-based catalysts [93-95].
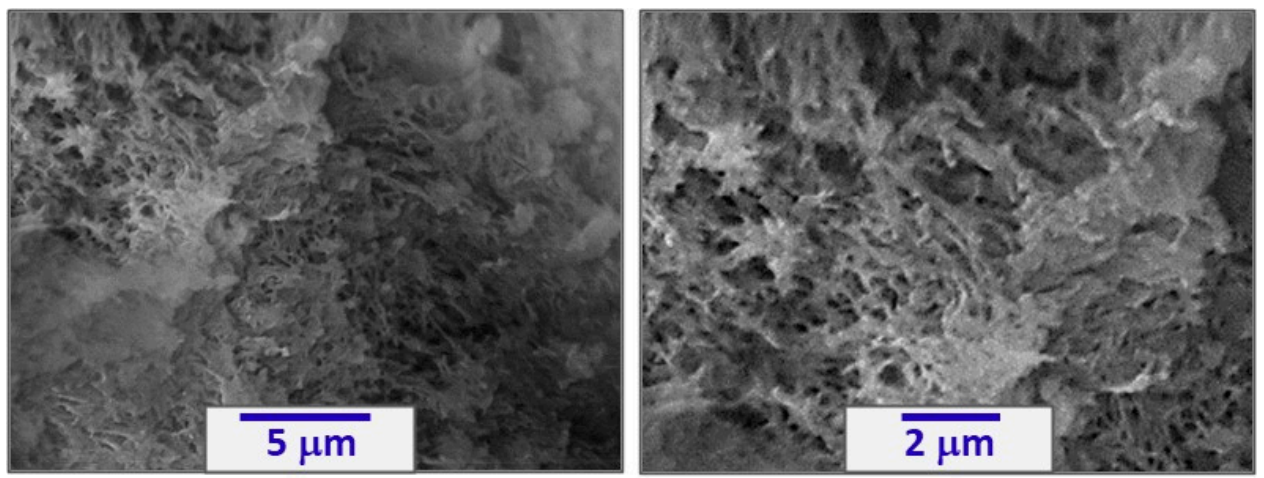

Figure 4. SEM images of PDCPD aerogels obtained from the ROMP of DCPD with $\mathbf{W}_{2} / \mathbf{N B D}$. 


\subsection{Swelling Studies}

We have shown recently that mostly-cis PDCPD xerogels synthesized with the $\mathbf{W}_{\mathbf{2}} / \mathbf{P A}$ catalytic system have the ability to absorb large amounts of organic solvents and swell $[75,81]$. This property is related with the mostly-cis structure of the polymer chain, as PDCPD xerogels and aerogels that have a significant trans-content swell less or do not swell at all [75,81]. PDCPD aerogels of this study could also swell in selected organic solvents (e.g., toluene, dichloromethane, THF, chloroform) by absorbing a significant amount of solvent. Compared to PDCPD materials obtained with the $\mathbf{W}_{2} / \mathbf{P A}$ catalytic system, the PDCPD aerogels of this work were sturdier. In the first case, the small chains of polyphenylacetylene were soluble and had to be removed, while in the present case, the small amount of PNBD that is formed is insoluble and cannot and does not need to be washed out. The fact that PDCPD aerogels derived with the $\mathbf{W}_{2} / \mathrm{NBD}$ catalytic system swell significantly, although PNBD is a crosslinked polymer, is important and may be attributed to the fact that those materials are not random copolymers, but PNBD chains are rather confined at the ends of the PDCPD chains. Furthermore, it should be pointed out that said swelling takes place fast, which is attributed to the synergistic effect of the open porosity of the aerogels, which provides rapid access of the solvent to their interior, and therefore the diffusion distance inside the rigid polymer is shortened and the response to the solvents of interest is accelerated.

We evaluated those aerogels versus their potential to be used as sensors. In the literature, there is a growing interest for the use of crosslinked polymers in the form of gels in chemical sensors [82-87]. For this kind of application, the swelling behavior of those gels needs to be examined [86,87]. Swelling is essentially a chain rearrangement, resulting from interactions between the polymer and its environment [87], which, in this case, is the solvent. In order for a gel to be used as a sensor, it has to show a fast volume change when exposed to external stimuli. For this fast response to be achieved, the gel dimensions need to be small.

For that reason, PDCPD aerogels in the form of thin disks were added in graduated glass tubes containing $5 \mathrm{~mL}$ of various neat organic solvents (toluene, dichloromethane, chloroform, chlorobenzene, bromobenzene, THF, 1-bromobutane, ethyl bromide, ethylene dichloride, $m$-xylene, $p$-xylene and mesitylene-Figure 5). The initial volume of the disks was $0.1 \mathrm{~mL}$ in all cases. Gels were kept in the solvent for $2 \mathrm{~h}$ in total and for the first hour the volume increase $(\Delta V)$ of gels in each solvent was measured every $10 \mathrm{~min}$. $\Delta V$ was determined by the volume decrease of each solvent when the gel was taken out of the graduated tube. Results are summarized in Table 2 and graphically represented in Figure 6. All plots (volume increase vs. time) are provided in the Supporting Information (Figures S4-S15). The higher volume increase was observed in chloroform, dichloromethane, THF and toluene, with the fastest response in chloroform and THF (300\% volume increase within the first $10 \mathrm{~min}$ ). In most of the solvents, the volume increase after $2 \mathrm{~h}$ did not change too much (Table 2; Figures S4-S15).

Table 2. Volume increase of PDCPD aerogel thin disks (initial volume $=0.1 \mathrm{~mL}$ ) in various organic solvents.

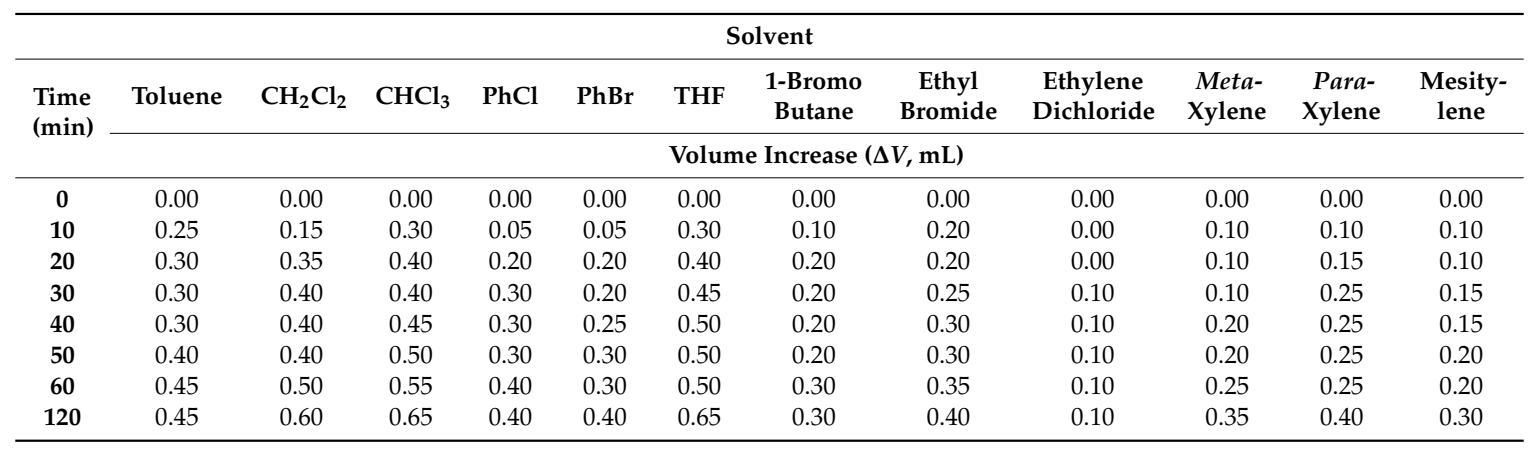



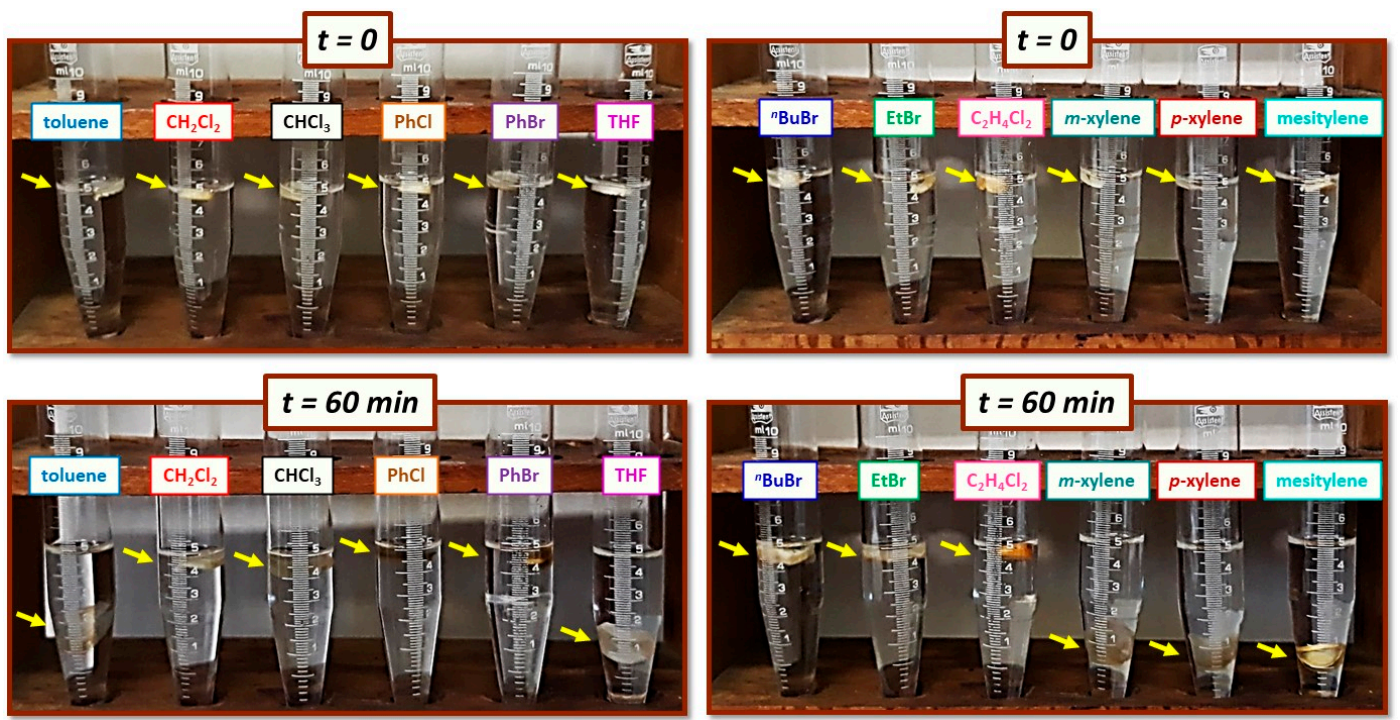

Figure 5. Representative optical photographs at two time intervals (top: $t=0 \mathrm{~min}$; bottom: $t=60 \mathrm{~min}$ ) of graduated tubes containing PDCPD aerogel thin disks and various organic solvents, as indicated. Yellow arrows point at the wet-gels.
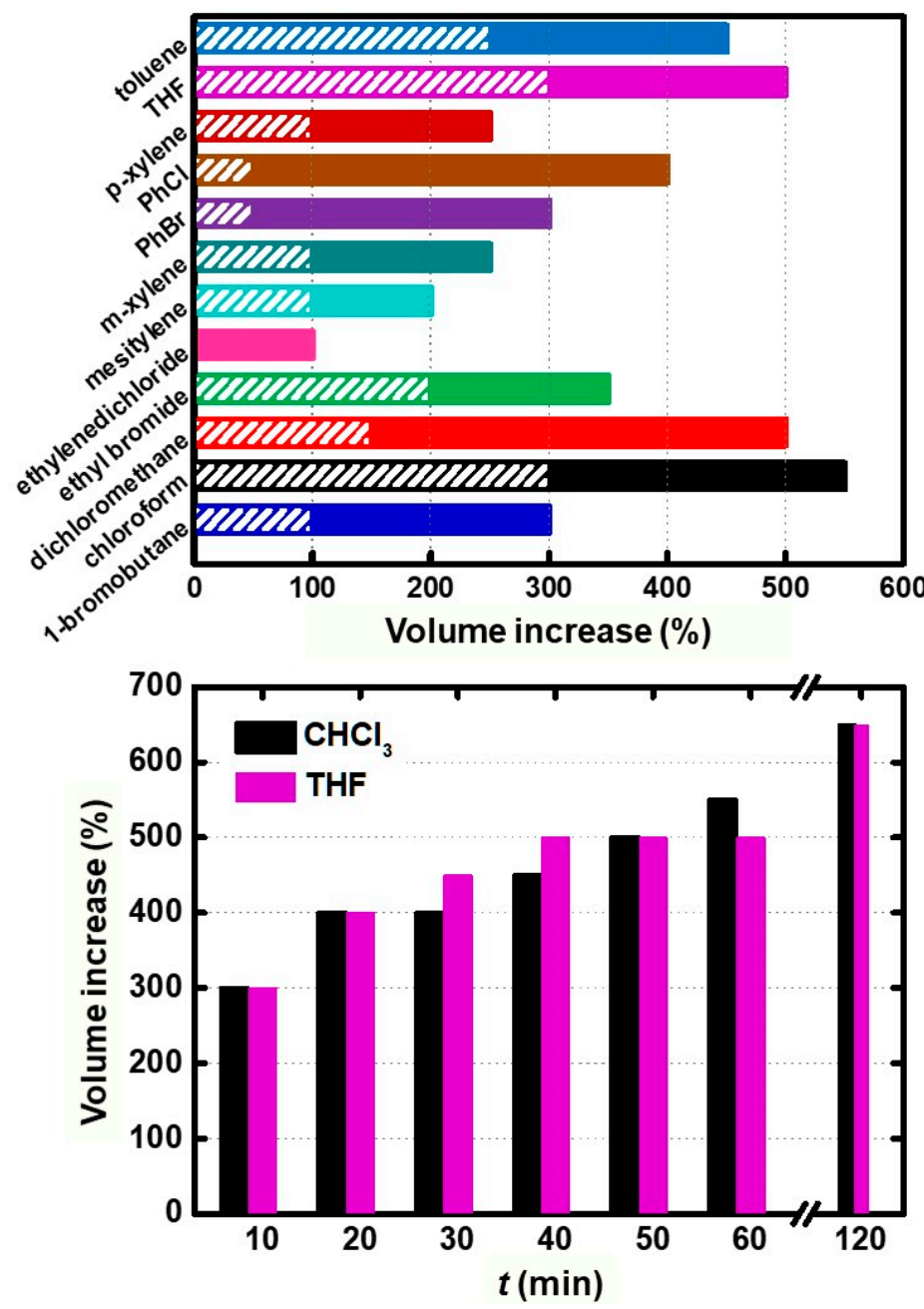

Figure 6. Top: Volume increase of thin PDCPD aerogel disks in various organic solvents at $10 \mathrm{~min}$ (shaded length of each column) and at $60 \mathrm{~min}$ (full length of each column). Bottom: Comparison of the volume increase of thin PDCPD aerogel disks in THF and chloroform within $120 \mathrm{~min}$. 


\section{Conclusions}

High-cis poly(dicyclopentadiene) (PDCPD) aerogels were synthesized via ROMP of dicyclopentadiene catalyzed using the ditungsten catalytic system, $\mathrm{Na}\left[\mathrm{W}_{2}(\mu-\mathrm{Cl})_{3} \mathrm{Cl}_{4}(\mathrm{THF})_{2}\right] \cdot(\mathrm{THF})_{3}$ $\left(\mathbf{W}_{2} ;\left(\mathrm{W}^{3} \mathrm{~W}\right)^{6+}, a^{\prime 2} e^{4}\right)$, and norbornadiene (NBD) as a co-initiator. High-cis PDCPD aerogels have several similarities with high-trans PDCPD aerogels obtained with Ru-based catalysts; for example, they are both macroporous materials with low BET surface areas (42 vs. $38 \mathrm{~m}^{2} / \mathrm{g}$ ) and fibrous morphologies. However, the aspect ratios of the two kinds of fibers were different and fibers from the high-cis polymer consisted of strings of beads, while fibers of the high-trans polymer were smooth, in agreement with our previous observations for high-cis and high-trans norbornene/norbornadiene copolymers. Most interestingly though, high-cis PDCPD aerogels absorb selected organic solvents and swell rapidly, in some cases up to 4 times their original volume within $10 \mathrm{~min}$, thus comprising viable candidates for applications in chemical sensors and solvent-responsive actuators. The advantage of aerogels versus xerogels or dense polymers for these applications is their open porosity, which provides rapid access of the solvent to their interior, which decreases the diffusion distance inside the polymer itself and accelerates the response to the solvents of interest.

Supplementary Materials: The following are available online at http://www.mdpi.com/2073-4360/12/5/1033/s1; Table S1: Formulations used for the synthesis of PDCPD xerogels and aerogels using the catalytic system $\mathbf{W}_{2} / \mathbf{N B D}$; Figure S1: Top row: ATR-FTIR spectra (left: 1700-1590 $\mathrm{cm}^{-1}$; right: $1500-675 \mathrm{~cm}^{-1}$ ) of PDCPD aerogels and xerogels obtained from ROMP of DCPD with three catalytic systems, as indicated. Bottom row: FT-Raman spectra (left: $3200-1200 \mathrm{~cm}^{-1}$; right: $1710-1590 \mathrm{~cm}^{-1}$ ) of PDCPD aerogels and xerogels obtained from the ROMP of DCPD with three catalytic systems, as indicated; Figure S2: ${ }^{13}$ C CPMAS NMR spectra of PDCPD aerogels obtained from ROMP of DCPD with three catalytic systems, as indicated; Figure S3: Weight loss with temperature (left) and derivative weight loss with temperature (right) of PDCPD aerogels and xerogels obtained from the ROMP of DCPD with three catalytic systems, as indicated; Figure S4: Swelling of a PDCPD aerogel thin disk in toluene versus time; Figure S5: Swelling of a PDCPD aerogel thin disk in dichloromethane versus time; Figure S6: Swelling of a PDCPD aerogel thin disk in chloroform versus time; Figure S7: Swelling of a PDCPD aerogel thin disk in chlorobenzene versus time; Figure S8: Swelling of a PDCPD aerogel thin disk in bromobenzene versus time; Figure S9: Swelling of a PDCPD aerogel thin disk in THF versus time; Figure S10: Swelling of a PDCPD aerogel thin disk in 1-bromobutane versus time; Figure S11: Swelling of a PDCPD aerogel thin disk in ethyl bromide versus time; Figure S12: Swelling of a PDCPD aerogel thin disk in ethylene dichloride versus time; Figure S13: Swelling of a PDCPD aerogel thin disk in $m$-xylene versus time; Figure S14: Swelling of a PDCPD aerogel thin disk in $p$-xylene versus time; Figure S15: Swelling of a PDCPD aerogel thin disk in mesitylene versus time.

Author Contributions: Methodology, P.P., B.B., D.C.; investigation and validation, P.P., D.C., G.R.; resources, P.P.; writing-original draft preparation, P.P., D.C.; writing—review and editing, P.P., D.C., G.R., B.B.; supervision, P.P.; funding acquisition, P.P. All authors have read and agreed to the published version of the manuscript.

Funding: This project has received funding from the European Union's Horizon 2020 research and innovation programme under grant agreement No. 685648. This publication reflects the views only of the authors, and the Commission cannot be held responsible for any use which may be made of the information contained therein. Partial funding

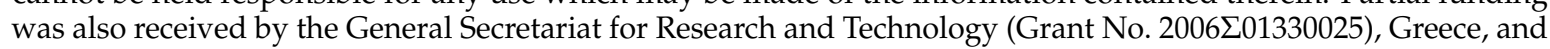
the Special Account of Research Grants of the National and Kapodistrian University of Athens.

Acknowledgments: We thank Ariadne Argyraki and Vassilis Skounakis (Department of Geology and Geoenvironment, NKUA, Athens, Greece) for assistance with SEM, Gregor Mali (National Institute of Chemistry, Ljubljana, Slovenia) for assistance with solid-state NMR, G. C. Anyfantis, G. D. Chryssikos and C. Tsiantos (National Hellenic Research Foundation, Athens, Greece) for assistance with ATR-FTIR and FT-Raman.

Conflicts of Interest: The authors declare no conflicts of interest.

\section{References}

1. Reim, M.; Körner, W.; Manara, J.; Korder, S.; Arduini-Schuster, M.; Ebert, H.-P.; Fricke, J. Silica aerogel granulate material for thermal insulation and daylighting. Sol. Energy 2005, 79, 131-139. [CrossRef]

2. Koebel, M.; Rigacci, A.; Achard, P. Aerogel-based thermal superinsulation: An overview. J. Sol-Gel Sci. Technol. 2012, 63, 315-339. [CrossRef]

3. Zhao, S.; Malfait, W.J.; Guerrero-Alburquerque, N.; Koebel, M.M.; Nyström, G. Biopolymer Aerogels and Foams: Chemistry, Properties, and Applications. Angew. Chem. Int. Ed. 2018, 57, 7580-7608. [CrossRef] [PubMed] 
4. Stepanian, C.J.; Gould, G.L.; Begag, R. Aerogel Composite with Fibrous Batting. U.S. Patent 7078359B2, 18 July 2006.

5. Malakooti, S.; Churu, H.G.; Lee, A.; Xu, T.; Luo, H.; Xiang, N.; Sotiriou-Leventis, C.; Leventis, N.; Lu, H. Sound insulation properties in low-density, mechanically strong and ductile nanoporous polyurea aerogels. J. Non-Cryst. Solids 2017, 476, 36-45. [CrossRef]

6. Malakooti, S.; Churu, H.G.; Lee, A.; Rostami, S.; May, S.J.; Ghidei, S.; Wang, F.; Lu, Q.; Luo, H.; Xiang, N.; et al. Sound Transmission Loss Enhancement in an Inorganic-Organic Laminated Wall Panel Using Multifunctional Low-Density Nanoporous Polyurea Aerogels: Experiment and Modeling. Adv. Eng. Mater. 2018, 20, 1700937. [CrossRef]

7. Mirzaeian, M.; Hall, P.J. Preparation of controlled porosity carbon aerogels for energy storage in rechargeable lithium oxygen batteries. Electrochim. Acta 2009, 54, 7444-7451. [CrossRef]

8. Biener, J.; Stadermann, M.; Suss, M.; Worsley, M.A.; Biener, M.M.; Rose, K.A.; Baumann, T.F. Advanced carbon aerogels for energy applications. Energy Environ. Sci. 2011, 4, 656-667. [CrossRef]

9. Kabbour, H.; Baumann, T.F.; Satcher, J.H.; Saulnier, A.; Ahn, C.C. Toward New Candidates for Hydrogen Storage: High-Surface-Area Carbon Aerogels. Chem. Mater. 2006, 18, 6085-6087. [CrossRef]

10. García-González, C.A.; Alnaief, M.; Smirnova, I. Polysaccharide-based aerogels-Promising biodegradable carriers for drug delivery systems. Carbohydr. Polym. 2011, 86, 1425-1438. [CrossRef]

11. García-González, C.A.; Smirnova, I. Use of supercritical fluid technology for the production of tailor-made aerogel particles for delivery systems. J. Supercrit. Fluids 2013, 79, 152-158. [CrossRef]

12. Martins, M.; Barros, A.A.; Quraishi, S.; Gurikov, P.; Raman, S.P.; Smirnova, I.; Duarte, A.R.C.; Reis, R.L. Preparation of macroporous alginate-based aerogels for biomedical applications. J. Supercrit. Fluids 2015, 106, 152-159. [CrossRef]

13. García-González, C.A.; Budtova, T.; Durães, L.; Erkey, C.; Del Gaudio, P.; Gurikov, P.; Koebel, M.; Liebner, F.; Neagu, M.; Smirnova, I. An Opinion Paper on Aerogels for Biomedical and Environmental Applications. Molecules 2019, 24, 1815. [CrossRef] [PubMed]

14. Batista, M.P.; Gonçalves, V.S.S.; Gaspar, F.B.; Nogueira, I.D.; Matias, A.A.; Gurikov, P. Novel alginate-chitosan aerogel fibres for potential wound healing applications. Int. J. Biol. Macromol. 2020. [CrossRef] [PubMed]

15. Mikkonen, K.S.; Parikka, K.; Ghafar, A.; Tenkanen, M. Prospects of polysaccharide aerogels as modern advanced food materials. Trends Food Sci. Technol. 2013, 34, 124-136. [CrossRef]

16. Korhonen, J.T.; Kettunen, M.; Ras, R.H.A.; Ikkala, O. Hydrophobic Nanocellulose Aerogels as Floating, Sustainable, Reusable, and Recyclable Oil Absorbents. ACS Appl. Mater. Interfaces 2011, 3, 1813-1816. [CrossRef]

17. Amonette, J.E.; Matyáš, J. Functionalized silica aerogels for gas-phase purification, sensing, and catalysis: A review. Microporous Mesoporous Mater. 2017, 250, 100-119. [CrossRef]

18. Maleki, H. Recent advances in aerogels for environmental remediation applications: A review. Chem. Eng. J. 2016, 300, 98-118. [CrossRef]

19. Wu, Z.-S.; Yang, S.; Sun, Y.; Parvez, K.; Feng, X.; Müllen, K. 3D Nitrogen-Doped Graphene Aerogel-Supported Fe3O4 Nanoparticles as Efficient Electrocatalysts for the Oxygen Reduction Reaction. J. Am. Chem. Soc. 2012, 134, 9082-9085. [CrossRef]

20. Maleki, H.; Hüsing, N. Current status, opportunities and challenges in catalytic and photocatalytic applications of aerogels: Environmental protection aspects. Appl. Catal. B Environ. 2018, 221, 530-555. [CrossRef]

21. Saeed, A.M.; Wisner, C.A.; Donthula, S.; Majedi Far, H.; Sotiriou-Leventis, C.; Leventis, N. Reuseable Monolithic Nanoporous Graphite-Supported Nanocatalysts (Fe, Au, Pt, Pd, Ni, and Rh) from Pyrolysis and Galvanic Transmetalation of Ferrocene-Based Polyamide Aerogels. Chem. Mater. 2016, 28, 4867-4877. [CrossRef]

22. Cai, B.; Eychmüller, A. Promoting Electrocatalysis upon Aerogels. Adv. Mater. 2019, 31, 1804881. [CrossRef] [PubMed]

23. Ziegler, C.; Wolf, A.; Liu, W.; Herrmann, A.-K.; Gaponik, N.; Eychmüller, A. Modern Inorganic Aerogels. Angew. Chem. Int. Ed. 2017, 56, 13200-13221. [CrossRef]

24. Rewatkar, P.M.; Taghvaee, T.; Saeed, A.M.; Donthula, S.; Mandal, C.; Chandrasekaran, N.; Leventis, T.; Shruthi, T.K.; Sotiriou-Leventis, C.; Leventis, N. Sturdy, Monolithic SiC and Si3N4 Aerogels from Compressed Polymer-Cross-Linked Silica Xerogel Powders. Chem. Mater. 2018, 30, 1635-1647. [CrossRef] 
25. Feinle, A.; Hüsing, N. Mixed metal oxide aerogels from tailor-made precursors. J. Supercrit. Fluids 2015, 106, 2-8. [CrossRef]

26. Gurikov, P.; Raman, S.P.; Weinrich, D.; Fricke, M.; Smirnova, I. A novel approach to alginate aerogels: Carbon dioxide induced gelation. RSC Adv. 2015, 5, 7812-7818. [CrossRef]

27. Paraskevopoulou, P.; Smirnova, I.; Athamneh, T.; Papastergiou, M.; Chriti, D.; Mali, G.; Čendak, T.; Chatzichristidi, M.; Raptopoulos, G.; Gurikov, P. Mechanically-Strong Polyurea/Polyurethane-Crosslinked Alginate Aerogels. ACS Appl. Polym. Mater. 2020, 2, 1974-1988. [CrossRef]

28. Baudron, V.; Taboada, M.; Gurikov, P.; Smirnova, I.; Whitehouse, S. Production of starch aerogel in form of monoliths and microparticles. Colloid Polym. Sci. 2020, 298, 477-494. [CrossRef]

29. Chen, H.-B.; Schiraldi, D.A. Flammability of Polymer/Clay Aerogel Composites: An Overview. Polym. Rev. 2018, 59, 1-24. [CrossRef]

30. Paraskevopoulou, P.; Gurikov, P.; Raptopoulos, G.; Chriti, D.; Papastergiou, M.; Kypritidou, Z.; Skounakis, V.; Argyraki, A. Strategies toward catalytic biopolymers: Incorporation of tungsten in alginate aerogels. Polyhedron 2018, 154, 209-216. [CrossRef]

31. Mandal, C.; Donthula, S.; Far, H.M.; Saeed, A.M.; Sotiriou-Leventis, C.; Leventis, N. Transparent, mechanically strong, thermally insulating cross-linked silica aerogels for energy-efficient windows. J. Sol-Gel Sci. Technol. 2019, 92, 84-100. [CrossRef]

32. Leventis, N.; Chandrasekaran, N.; Sadekar, A.G.; Mulik, S.; Sotiriou-Leventis, C. The effect of compactness on the carbothermal conversion of interpenetrating metal oxide/resorcinol-formaldehyde nanoparticle networks to porous metals and carbides. J. Mater. Chem. 2010, 20, 7456-7471. [CrossRef]

33. Rewatkar, P.M.; Soni, R.U.; Sotiriou-Leventis, C.; Leventis, N. A Cobalt Sunrise: Thermites Based on $\mathrm{LiClO}_{4}$-Filled $\mathrm{Co}(0)$ Aerogels Prepared from Polymer-Cross-Linked Cobaltia Xerogel Powders. ACS Appl. Mater. Interfaces 2019, 11, 22668-22676. [CrossRef] [PubMed]

34. Wang, L.; Xu, H.; Gao, J.; Yao, J.; Zhang, Q. Recent progress in metal-organic frameworks-based hydrogels and aerogels and their applications. Coord. Chem. Rev. 2019, 398, 213016. [CrossRef]

35. Alshrah, M.; Tran, M.-P.; Gong, P.; Naguib, H.E.; Park, C.B. Development of high-porosity resorcinol formaldehyde aerogels with enhanced mechanical properties through improved particle necking under $\mathrm{CO}_{2}$ supercritical conditions. J. Colloid Interface Sci. 2017, 485, 65-74. [CrossRef] [PubMed]

36. Mulik, S.; Sotiriou-Leventis, C.; Leventis, N. Time-Efficient Acid-Catalyzed Synthesis of Resorcinol-Formaldehyde Aerogels. Chem. Mater. 2007, 19, 6138-6144. [CrossRef]

37. Mulik, S.; Sotiriou-Leventis, C.; Leventis, N. Macroporous Electrically Conducting Carbon Networks by Pyrolysis of Isocyanate-Cross-Linked Resorcinol-Formaldehyde Aerogels. Chem. Mater. 2008, 20, 6985-6997. [CrossRef]

38. Williams, J.C.; Nguyen, B.N.; McCorkle, L.; Scheiman, D.; Griffin, J.S.; Steiner, S.A.; Meador, M.A.B. Highly Porous, Rigid-Rod Polyamide Aerogels with Superior Mechanical Properties and Unusually High Thermal Conductivity. ACS Appl. Mater. Interfaces 2017, 9, 1801-1809. [CrossRef]

39. Leventis, N.; Chidambareswarapattar, C.; Mohite, D.P.; Larimore, Z.J.; Lu, H.; Sotiriou-Leventis, C. Multifunctional porous aramids (aerogels) by efficient reaction of carboxylic acids and isocyanates. J. Mater. Chem. 2011, 21, 11981-11986. [CrossRef]

40. Williams, J.C.; Meador, M.A.B.; McCorkle, L.; Mueller, C.; Wilmoth, N. Synthesis and Properties of Step-Growth Polyamide Aerogels Cross-linked with Triacid Chlorides. Chem. Mater. 2014, 26, 4163-4171. [CrossRef]

41. Chidambareswarapattar, C.; Larimore, Z.; Sotiriou-Leventis, C.; Mang, J.T.; Leventis, N. One-step room-temperature synthesis of fibrous polyimide aerogels from anhydrides and isocyanates and conversion to isomorphic carbons. J. Mater. Chem. 2010, 20, 9666-9678. [CrossRef]

42. Leventis, N.; Sotiriou-Leventis, C.; Mohite, D.P.; Larimore, Z.J.; Mang, J.T.; Churu, G.; Lu, H. Polyimide Aerogels by Ring-Opening Metathesis Polymerization (ROMP). Chem. Mater. 2011, 23, 2250-2261. [CrossRef]

43. Chidambareswarapattar, C.; Xu, L.; Sotiriou-Leventis, C.; Leventis, N. Robust monolithic multiscale nanoporous polyimides and conversion to isomorphic carbons. RSC Adv. 2013, 3, 26459-26469. [CrossRef]

44. Meador, M.A.B.; Agnello, M.; McCorkle, L.; Vivod, S.L.; Wilmoth, N. Moisture-Resistant Polyimide Aerogels Containing Propylene Oxide Links in the Backbone. ACS Appl. Mater. Interfaces 2016, 8, 29073-29079. [CrossRef] 
45. Meador, M.A.B.; Alemán, C.R.; Hanson, K.; Ramirez, N.; Vivod, S.L.; Wilmoth, N.; McCorkle, L. Polyimide Aerogels with Amide Cross-Links: A Low Cost Alternative for Mechanically Strong Polymer Aerogels. ACS Appl. Mater. Interfaces 2015, 7, 1240-1249. [CrossRef]

46. Guo, H.; Meador, M.A.B.; McCorkle, L.S.; Scheiman, D.A.; McCrone, J.D.; Wilkewitz, B. Poly(maleic anhydride) cross-linked polyimide aerogels: Synthesis and properties. RSC Adv. 2016, 6, 26055-26065. [CrossRef]

47. Vivod, S.L.; Meador, M.A.B.; Pugh, C.; Wilkosz, M.; Calomino, K.; McCorkle, L. Toward Improved Optical Transparency of Polyimide Aerogels. ACS Appl. Mater. Interfaces 2020, 12, 8622-8633. [CrossRef]

48. Chidambareswarapattar, C.; McCarver, P.M.; Luo, H.; Lu, H.; Sotiriou-Leventis, C.; Leventis, N. Fractal Multiscale Nanoporous Polyurethanes: Flexible to Extremely Rigid Aerogels from Multifunctional Small Molecules. Chem. Mater. 2013, 25, 3205-3224. [CrossRef]

49. Kanellou, A.; Anyfantis, G.C.; Chriti, D.; Raptopoulos, G.; Pitsikalis, M.; Paraskevopoulou, P. Poly(urethane-norbornene) Aerogels via Ring Opening Metathesis Polymerization of Dendritic UrethaneNorbornene Monomers: Structure-Property Relationships as a Function of an Aliphatic Versus an Aromatic Core and the Number of Peripheral Norbornene Moieties. Molecules 2018, 23, 1007. [CrossRef]

50. Leventis, N.; Sotiriou-Leventis, C.; Chidambareswarapattar, C. Porous Polyurethane Networks and Methods of Preparation. U.S. Patent 20180251623A1, 6 September 2018.

51. Papastergiou, M.; Kanellou, A.; Chriti, D.; Raptopoulos, G.; Paraskevopoulou, P. Poly(Urethane-Acrylate) Aerogels via Radical Polymerization of Dendritic Urethane-Acrylate Monomers. Materials 2018, 11, 2249. [CrossRef]

52. Papastergiou, M.; Chriti, D.; Damalas, D.E.; Raptopoulos, G.; Paraskevopoulou, P. Poly(urethane-acrylate) aerogels from the isocyanurate trimer of isophorone diisocyanate. J. Supercrit. Fluids 2019, 148, 42-54. [CrossRef]

53. Bang, A.; Buback, C.; Sotiriou-Leventis, C.; Leventis, N. Flexible Aerogels from Hyperbranched Polyurethanes: Probing the Role of Molecular Rigidity with Poly(Urethane Acrylates) Versus Poly(Urethane Norbornenes). Chem. Mater. 2014, 26, 6979-6993. [CrossRef]

54. Taghvaee, T.; Donthula, S.; Rewatkar, P.M.; Majedi Far, H.; Sotiriou-Leventis, C.; Leventis, N. K-Index: A Descriptor, Predictor, and Correlator of Complex Nanomorphology to Other Material Properties. ACS Nano 2019, 13, 3677-3690. [CrossRef]

55. Chriti, D.; Raptopoulos, G.; Papastergiou, M.; Paraskevopoulou, P. Millimeter-Size Spherical Polyurea Aerogel Beads with Narrow Size Distribution. Gels 2018, 4, 66. [CrossRef]

56. Leventis, N.; Sotiriou-Leventis, C.; Chandrasekaran, N.; Mulik, S.; Larimore, Z.J.; Lu, H.; Churu, G.; Mang, J.T. Multifunctional Polyurea Aerogels from Isocyanates and Water. A Structure-Property Case Study. Chem. Mater. 2010, 22, 6692-6710. [CrossRef]

57. Paraskevopoulou, P.; Chriti, D.; Raptopoulos, G.; Anyfantis, G.C. Synthetic Polymer Aerogels in Particulate Form. Materials 2019, 12, 1543. [CrossRef]

58. Leventis, N.; Sotiriou-Leventis, C.; Saeed, A.M.; Donthula, S.; Majedi Far, H.; Rewatkar, P.M.; Kaiser, H.; Robertson, J.D.; Lu, H.; Churu, G. Nanoporous Polyurea from a Triisocyanate and Boric Acid: A Paradigm of a General Reaction Pathway for Isocyanates and Mineral Acids. Chem. Mater. 2016, 28, 67-78. [CrossRef]

59. Ho Kim, S.; Worsley, M.A.; Valdez, C.A.; Shin, S.J.; Dawedeit, C.; Braun, T.; Baumann, T.F.; Letts, S.A.; Kucheyev, S.O.; Jen, J.; et al. Exploration of the versatility of ring opening metathesis polymerization: An approach for gaining access to low density polymeric aerogels. RSC Adv. 2012, 2, 8672-8680. [CrossRef]

60. Lee, J.K.; Gould, G.L. Polydicyclopentadiene based aerogel: A new insulation material. J. Sol-Gel Sci. Technol. 2007, 44, 29-40. [CrossRef]

61. Mohite, D.P.; Mahadik-Khanolkar, S.; Luo, H.; Lu, H.; Sotiriou-Leventis, C.; Leventis, N. Polydicyclopentadiene aerogels grafted with PMMA: I. Molecular and interparticle crosslinking. Soft Matter 2013, 9, 1516-1530. [CrossRef]

62. Mohite, D.P.; Mahadik-Khanolkar, S.; Luo, H.; Lu, H.; Sotiriou-Leventis, C.; Leventis, N. Polydicyclopentadiene aerogels grafted with PMMA: II. Nanoscopic characterization and origin of macroscopic deformation. Soft Matter 2013, 9, 1531-1539. [CrossRef]

63. Bang, A.; Mohite, D.; Saeed, A.M.; Leventis, N.; Sotiriou-Leventis, C. Polydicyclopentadiene aerogels from first- versus second-generation Grubbs' catalysts: A molecular versus a nanoscopic perspective. J. Sol-Gel Sci. Technol. 2015, 75, 460-474. [CrossRef] 
64. Kim, S.H.; Shin, S.J.; Lenhardt, J.M.; Braun, T.; Sain, J.D.; Valdez, C.A.; Leif, R.N.; Kucheyev, S.O.; Wu, K.J.J.; Biener, J.; et al. Deterministic Control over High-Z Doping of Polydicyclopentadiene-Based Aerogel Coatings. ACS Appl. Mater. Interfaces 2013, 5, 8111-8119. [CrossRef]

65. Lee, J.K.; Gould, G.L. Microporous Polyolefin-Based Aerogels. U.S. Patent 9469739B2, 18 October 2016.

66. Sutthasupa, S.; Shiotsuki, M.; Sanda, F. Recent advances in ring-opening metathesis polymerization, and application to synthesis of functional materials. Polym. J. 2010, 42, 905-915. [CrossRef]

67. Leitgeb, A.; Wappel, J.; Slugovc, C. The ROMP toolbox upgraded. Polymer 2010, 51, 2927-2946. [CrossRef]

68. Nomura, K.; Abdellatif, M.M. Precise synthesis of polymers containing functional end groups by living ring-opening metathesis polymerization (ROMP): Efficient tools for synthesis of block/graft copolymers. Polymer 2010, 51, 1861-1881. [CrossRef]

69. Slugovc, C. Industrial Applications of Olefin Metathesis Polymerization. In Olefin Metathesis; John Wiley \& Sons, Ltd.: Hoboken, NJ, USA, 2014; pp. 329-333, ISBN 978-1-118-71161-3.

70. Robertson, I.D.; Yourdkhani, M.; Centellas, P.J.; Aw, J.E.; Ivanoff, D.G.; Goli, E.; Lloyd, E.M.; Dean, L.M.; Sottos, N.R.; Geubelle, P.H.; et al. Rapid energy-efficient manufacturing of polymers and composites via frontal polymerization. Nature 2018, 557, 223-227. [CrossRef]

71. Davidson, T.A.; Wagener, K.B.; Priddy, D.B. Polymerization of Dicyclopentadiene: A Tale of Two Mechanisms. Macromolecules 1996, 29, 786-788. [CrossRef]

72. Della Martina, A.; Hilborn, J.G.; Mühlebach, A. Macroporous Cross-Linked Poly(dicyclopentadiene). Macromolecules 2000, 33, 2916-2921. [CrossRef]

73. Rule, J.D.; Moore, J.S. ROMP Reactivity of endo- and exo-Dicyclopentadiene. Macromolecules 2002, 35, 7878-7882. [CrossRef]

74. Autenrieth, B.; Jeong, H.; Forrest, W.P.; Axtell, J.C.; Ota, A.; Lehr, T.; Buchmeiser, M.R.; Schrock, R.R. Stereospecific Ring-Opening Metathesis Polymerization (ROMP) of endo-Dicyclopentadiene by Molybdenum and Tungsten Catalysts. Macromolecules 2015, 48, 2480-2492. [CrossRef]

75. Raptopoulos, G.; Anyfantis, G.C.; Chriti, D.; Paraskevopoulou, P. Synthesis and structural characterization of poly(dicyclopentadiene) gels obtained with a novel ditungsten versus conventional $\mathrm{W}$ and Ru mononuclear catalysts. Inorg. Chim. Acta 2017, 460, 69-76. [CrossRef]

76. Floros, G.; Saragas, N.; Paraskevopoulou, P.; Psaroudakis, N.; Koinis, S.; Pitsikalis, M.; Hadjichristidis, N.; Mertis, K. Ring Opening Metathesis Polymerization of Norbornene and Derivatives by the Triply Bonded Ditungsten Complex $\mathrm{Na}\left[\mathrm{W}_{2}\left(\mu-\mathrm{Cl}_{3} \mathrm{Cl}_{4}(\mathrm{THF})_{2}\right] \cdot(\mathrm{THF})_{3}\right.$. Polymers 2012, 4, 1657-1673. [CrossRef]

77. Floros, G.; Agrafioti, F.; Grigoropoulos, A.; Paraskevopoulou, P.; Mertis, K.; Tseklima, M.; Veli, M.; Pitsikalis, M. Statistical copolymers of norbornene and 5-vinyl-2-norbornene by a ditungsten complex mediated ring-opening metathesis Polymerization: Synthesis, thermal properties, and kinetics of thermal decomposition. J. Polym. Sci. Part A Polym. Chem. 2013, 51, 4835-4844. [CrossRef]

78. Saragas, N.; Floros, G.; Raptopoulos, G.; Pitsikalis, M.; Paraskevopoulou, P.; Mertis, K. Exploring the Reactivity of $\mathrm{Na}\left[\mathrm{W}_{2}(\mu-\mathrm{Cl})_{3} \mathrm{Cl}_{4}(\mathrm{THF})_{2}\right] \cdot(\mathrm{THF})_{3}$ towards the Polymerization of Selected Cycloolefins. Molecules 2015, 20, 21896-21908. [CrossRef]

79. Raptopoulos, G.; Kyriakou, K.; Mali, G.; Scarpellini, A.; Anyfantis, G.C.; Mavromoustakos, T.; Pitsikalis, M.; Paraskevopoulou, P. Copolymerization of Norbornene and Norbornadiene Using a cis-Selective Bimetallic W-Based Catalytic System. Polymers 2017, 9, 141. [CrossRef]

80. Chriti, D.; Grigoropoulos, A.; Raptopoulos, G.; Charalambidis, G.; Nikolaou, V.; Coutsolelos, A.G.; Pitsikalis, M.; Mertis, K.; Paraskevopoulou, P. Metathesis Polymerization Reactions Induced by the Bimetallic Complex $\left(\mathrm{Ph}_{4} \mathrm{P}\right)_{2}\left[\mathrm{~W}_{2}(\mu-\mathrm{Br})_{3} \mathrm{Br}_{6}\right]$. Polymers 2015, 7, 2611-2624. [CrossRef]

81. Chriti, D.; Raptopoulos, G.; Anyfantis, G.C.; Paraskevopoulou, P. An Extreme Case of Swelling of Mostly cis-Polydicyclopentadiene by Selective Solvent Absorption-Application in Decontamination and Environmental Remediation. ACS Appl. Polym. Mater. 2019, 1, 1648-1659. [CrossRef]

82. Guenther, M.; Gerlach, G.; Corten, C.; Kuckling, D.; Muller, M.; Shi, Z.; Sorber, J.; Arndt, K.-F. Application of Polyelectrolytic Temperature-Responsive Hydrogels in Chemical Sensors. Macromol. Symp. 2007, 254, 314-321. [CrossRef]

83. Zhao, Q.; Dunlop, J.W.C.; Qiu, X.; Huang, F.; Zhang, Z.; Heyda, J.; Dzubiella, J.; Antonietti, M.; Yuan, J. An instant multi-responsive porous polymer actuator driven by solvent molecule sorption. Nat. Commun. 2014, 5, 1-8. [CrossRef] 
84. Schute, K.; Jansen, F.; Rose, M. Solvent-Responsive and Switchable Nanofiltration Membranes based on Hypercrosslinked Polymers with Permanent Porosity. ChemNanoMat 2018, 4, 562-567. [CrossRef]

85. Shiraki, T.; Dawn, A.; Tsuchiya, Y.; Shinkai, S. Thermo- and Solvent-Responsive Polymer Complex Created from Supramolecular Complexation between a Helix-Forming Polysaccharide and a Cationic Polythiophene. J. Am. Chem. Soc. 2010, 132, 13928-13935. [CrossRef]

86. Ehrenhofer, A.; Elstner, M.; Wallmersperger, T. Normalization of hydrogel swelling behavior for sensoric and actuatoric applications. Sens. Actuators B Chem. 2018, 255, 1343-1353. [CrossRef]

87. Gerlach, G.; Arndt, K.-F. (Eds.) Hydrogel Sensors and Actuators: Engineering and Technology; Springer Series on Chemical Sensors and Biosensors; Springer: Berlin/Heidelberg, Germany, 2010; ISBN 978-3-540-75644-6.

88. Chisholm, M.H.; Eichhorn, B.W.; Folting, K.; Huffman, J.C.; Ontiveros, C.D.; Streib, W.E.; Van der Sluys, W.G. Preparation and characterization of $\mathrm{NaW}_{2} \mathrm{Cl}_{7}(\mathrm{THF})_{5}$. A synthetically useful precursor for $\mathrm{X}_{3} \mathrm{~W} \equiv \mathrm{WX}_{3}$ compounds where $\mathrm{X}=\mathrm{CH}_{2}-t-\mathrm{Bu}, \mathrm{NMe}_{2}$ and $\mathrm{O}-t-\mathrm{Bu}$. Inorg. Chem. 1987, 26, 3182-3186. [CrossRef]

89. Abadie, M.J.; Dimonie, M.; Couve, C.; Dragutan, V. New catalysts for linear polydicyclopentadiene synthesis. Eur. Polym. J. 2000, 36, 1213-1219. [CrossRef]

90. Saragas, N. Selective Polymerization of Alkynes and Cycloolefins with Bimetallic Complexes of the Transition Metals. Ph.D. Thesis, National and Kapodistrian University of Athens, Athens, Greece, 2009.

91. Barnes, S.E.; Brown, E.C.; Corrigan, N.; Coates, P.D.; Harkin-Jones, E.; Edwards, H.G.M. Raman spectroscopic studies of the cure of dicyclopentadiene (DCPD). Spectrochim. Acta Part A Mol. Biomol. Spectrosc. 2005, 61, 2946-2952. [CrossRef]

92. Schaubroeck, D.; Brughmans, S.; Vercaemst, C.; Schaubroeck, J.; Verpoort, F. Qualitative FT-Raman investigation of the ring opening metathesis polymerization of dicyclopentadiene. J. Mol. Catal. A Chem. 2006, 254, 180-185. [CrossRef]

93. Carvalho, V.P., Jr.; Ferraz, C.P.; Lima-Neto, B.S. Tailored norbornene-based copolymer with systematic variation of norbornadiene as a crosslinker obtained via ROMP with alternative amine Ru catalysts. Eur. Polym. J. 2012, 48, 341-349. [CrossRef]

94. Ferraz, C.P.; Fonseca, L.R.; Tomazetti, V.; Silva, F.C.S.; Lima-Neto, B.S.; Carvalho, V.P. Copolymers from norbornene and norbornadiene with organized morphologies and high Tg values obtained via ROMP with a highly reactive $\left[\mathrm{RuCl}_{3}\left(\mathrm{PCy}_{3}\right)_{2}\right]$ complex. New J. Chem. 2016, 40, 9424-9431. [CrossRef]

95. Chaves, H.K.; Ferraz, C.P.; Carvalho, V.P., Jr.; Lima-Neto, B.S. Tuning the activity of alternative Ru-based initiators for ring-opening metathesis polymerization of norbornene and norbornadiene by the substituent in 4- $\mathrm{CH}_{2}$ R-piperidine. J. Mol. Catal. A Chem. 2014, 385, 46-53. [CrossRef] 